\title{
Implementing Ethics in Information Systems, Presuppositions and Consequences in Ethics and Information Systems
}

\author{
Laurence Masclet $^{1}$ and Philippe Goujon ${ }^{2}$ \\ ${ }^{1}$ Facultés Notre Dame de la Paix, FUNDP, Belgium. \\ laurence.mascletafundp.ac.be \\ ${ }^{2}$ Facultés Notre Dame de la Paix, FUNDP, Belgium \\ pgo@info. fundp. ac. be
}

\begin{abstract}
This paper focuses on the relationship between information systems and ethics, and in particular, on the complexity of implementing ethics in information systems. Both fields are subject to various presuppositions that have consequences for how they manage the relationship of ethics implementation. Those presuppositions are related to the problem of "the construction of the norm" and the relationship - or absence of it in most governance theories - between norms and context. Ethicists seem to be reluctant to take into account the field of application of the norms created by the procedure it constructs. This is due mainly to a certain closure to elements other than rational argumentation in procedural ethics. Information systems' professionals, as we have seen in a study undertaken for the IDEGOV $^{1}$ project, also have a narrow vision of what is ethics. They often reduce ethics to a constraint that has to be fulfilled. They also have a very stereotypical vision of what are the issues present in the field of information systems - privacy, surveillance, and security - and how to answer these questions, mainly through more information. We will show that these presuppositions on both sides have a huge impact on the manner in which ethics is "done" in technical projects, and more importantly, we will give hints on how to improve the relationship. The term implementation is itself inappropriate, because it supposes that ethics is something external to information systems. This presupposition is shared to some extent by both fields i.e., ethics and information systems: it is the central point where we see the problem, but also the solution. Working on the framings of both ethical and technical communities is for us the way to overcome ethical problems in information system, and to reach appropriate ethical technology development.
\end{abstract}

Keywords: comprehensive proceduralism, ethics, governance, information systems, technology assessment.

${ }^{1}$ IDEGOV "IDEntification and GOVernance of ethical issues in information systems" is a project funded by the Club Informatique des Grandes Entreprises Françaises (CIGREF) foundation. It aims at giving ethical governance recommendations to information systems' professionals and organisations. It does so on the grounds of theoretical background development (a grid of analysis, and determination of parameters) and an empirical study, based on interviews and questionnaires made among information systems' professionals around the world on the basis of the grid of analysis. 


\section{Introduction}

Ethics is increasingly being recognized as a necessity in the field of information systems and in every technological project. There are some common features to every project involving technological development. Every project has to be ethically developed. This means that a project cannot just be submitted for ethical assessment when it has been completely developed.

Indeed, the very existence of a technology has an ethical impact, whether or not the technology is accepted by an ethical committee to be implemented in society. Nuclear power, for example, has an impact, whether it is used or not. The existence of a virus so powerful that it can kill half the population of the earth is of ethical preoccupation, no matter how secure and well protected it is. It is the virus's development and very existence itself that has to be evaluated. The conception that a piece of research is just research, that a technology is itself neutral before being used and, therefore, that it is the implementation that matters and has to be ethical, has caused a lot of misconceptions about the role of ethics. This is still a view that is prevalent in the technological and scientific world, even though it is starting to change at the political level. Projects are beginning to be stopped for ethical reasons, but this event is still very rare.

Ethical reflection has to play a part in every technology development project. In this paper, we will see what that means for technologies and for ethics, and how ethics has to change itself to take into account more parameters in its conceptions of itself and its procedure. However, first, we have to understand the specificities of the field of information systems.

\section{Ethical Specificities of Information Systems}

Information systems are well implemented in society. Its area of technological development does not seem to raise the problem of acceptance. As stated by Van den Hoven [24], information technologies have the particularity of being ubiquitous and persuasive. The main specificity of information systems is their links with information. Because information is such a positive value nowadays, information systems (which are comprised by information technology (IT)), seem to carry a positive bias by association. Indeed, with the development of cybernetics through the work of Wiener, Von Neumann, and Turing, information started to replace other values in the public sphere. Information seemed to be the best way to forget those morals and ideals that had been devaluated by the barbarism of two world wars. From its start as a strictly mathematical concept, information has invaded step by step every sphere of society, and become an ideology - a development that we can see in the work of Wiener [27]. Information and communication became the prevalent values of post-war society, and are still largely unquestioned.

This is partly why information systems seem so harmless in society. Nobody will ever say that they need less information, because information and communication are associated with the morally "good". Information and communication carry positive moral values. Actually, they became moral values. As a consequence, they are a very convenient instrument of persuasion and manipulation. 
To explore the field of information systems and ethics in information systems, in the IDEGOV project, we questioned information systems professionals on the ethical issues of information systems [14]. We found two main invading types of ethical worries: the first ethical worry was privacy, and the second was security, but these two concerns are usually linked together. Surveillance was also mentioned a lot, and can be considered a middle term between the two types of ethical worries. Not surprisingly, the solutions that are raised by almost everyone to these three concerns involve more information: for example, "raise awareness of the issue", "inform people", and "educate users and professionals".

Such a consensual way of thinking has, however, some background difficulties. One of the problems with offering information on ethical issues as an answer is that it does not address the existence of the ethical issue itself, in the sense that information on its own does not involve a reflection on the legitimacy of the technology. The technology itself is not questioned when someone offers the answer of awareness. Information is an a posteriori response to a technology that is already judged as inevitable. The ethical issues are therefore seen as inevitable, and the only strategy left is to "take [the technology] into account", and to "be aware" of its possible impacts. If the only solution to ethical problems in information systems is more information, then the system is in a loop. The system tries to heal itself by implementing education and ethical awareness, in order to get rid of ethical worries, but not every ethical issue can be solved by more information.

This focus on information is also partly due to the migration of the bioethical grid of analysis to the problem of governance [23]. Because bioethics is more developed than governance or at least has managed a better implementation, the bioethical way to deal with issues - awareness, informed consent, and so on - became the only way to judge ethical issues. However, some ethical issues are embedded in the information system itself, and can only be resolved by deeply changing the system or even withdrawing from a specific technological development. Ethics needs an engagement that cannot be reduced to awareness. Reducing ethics to a manageable scheme is very tempting, but it can make problems worse. To avoid paying the price of living in an unethical society, we should be ready to pay the price of ethics.

The development of a particular technology can and should be questioned ${ }^{2}$. Norms exist to regulate technological development and applications and, in the absence of

${ }^{2}$ Technology is already increasingly being questioned. The European Commission seems to care more and more about ethical problems and the shortcomings of the approach to ethics in research projects that it uses (such as an ethics check-list). On the academic side, a lot of studies have been conducted on this issue in recent years (see, for example [25]). We can also refer to the various publications of the International Federation of Information Processing's special interest group on the framework of the ethics of computing on this subject. Philosophers, scientists, developers and politicians appear to care increasingly about these issues. This can provide a good field for change if they think carefully about the presuppositions embedded in their respective approaches. In that sense, we see this IDEGOV-related work as a step before the elaboration of strategies to deal with the obligation to create guidelines and develop methods or meta-methods to implement reflexivity in technology assessment. This step aims at pointing out the common presuppositions and considerations that are not always taken into account by researchers in ethics and in technology. 
such norms, they can be constructed. The ways to construct ethical norms and to reach governance is one of the main questions of ethics. However, by taking only the problem of the construction of norms into account, ethics seems to have missed the opportunity to rally together technology developers and scientists. This is why ethical issues in information systems, as in any technological field, are not solely a matter of presupposition on the part of the technology developers. We cannot only blame misconceptions and prejudices from the field. We have to think about ethics and ethical theories and the way they address the issue of implementation of their own theories. Ethics can be a field for preconceptions and presuppositions. We have to take a critical stand on ethics and ethical theories themselves, in order to fully understand the problem of implementation of ethics in information systems.

\section{Ethics as a Question}

Many ethical theories focus on the procedures of the construction of norms. The philosophical trend that has the task of creating such procedures is called proceduralism. Proceduralism has taken various forms throughout history. The most famous sets of procedures have been written by Habermas and Rawls. But the proceduralism trend cannot be reduced to the work of these two philosophers.

"Proceduralism as a general idea encompasses any sort of procedural device for making a decision or resolving a dispute. It takes different forms ${ }^{3}$. In democratic polities, procedures can specify everything from the forms of participation and adjudication to the forms of implementation. These democratic preoccupations drive the current literature ${ }^{4}$. Joshua Cohen sees democracy as a "procedure that institutionalizes an idea of citizens as equals." For John Rawls, the only political consensus we can reasonably hope for is confined to democratic political procedures," such as the "right to vote and freedom of political speech and association, and whatever else is required for the electoral and legislative procedures of democracy." 6 Jürgen

\footnotetext{
${ }^{3}$ As a procedure by which conflicts may be settled, Brian Barry, Political Argument (London: Routledge and Kegan Paul, 1970) p. 85-91, distinguishes combat, bargaining, discussion on merits, voting, context, and authoritative determination.

${ }^{4}$ David Estlund, "Beyond Fairness and Deliberation: The Epistemic Dimension of Democratic Authority" in James Bohman and William Rehg, (ed.), Deliberative Democracy: Essay on Reason and Politics (Cambridge MIT Press, 1997); Allan Gibbard, "Morality as Consistency in Living: Korsgaard's Kantian Lectures" Ethics 110 (1999); Axel Honneth "Democracy as Reflexive Cooperation: John Dewey and the Theory of Democracy Today" Political Theory 26 (1998); Lenore Langsdorf and Darrin Hicks, "Regulating Disagreement, Constituting Participants: A Critique of Proceduralist Theories of Democracy" Argumentation 13 (1999); Michel Rosenfeld, “A Pluralist Critique of Contractarian Proceduralism”, Ratio Juris 11 (1998).

5 Joshua Cohen, "Pluralism and Proceduralism", Chicago-Kent Law Review, 69, (1994), p. 610.

${ }^{6}$ John Rawls, Political Liberalism (New York: Columbia University Press, 1993), p. 159.
} 
Habermas claims that the "central element of the democratic process resides in the procedure of deliberative politics. "7 [4]

Proceduralism is the product of our societies' pluralism (in particular the passage to multiple sources of normativity ${ }^{8}$ ). It was initially developed to resolve value conflicts by taking formal, "procedural" steps, and restricting debates to the level of rational argumentation. This trend has been very active in the field of ethics and governance, and has been very influential both with regard to the construction of procedures to assess technologies and political systems.

However, proceduralism has a blind spot that has had major consequences for the relationship between ethics and technologies [10]. Proceduralism focuses on norm construction but has, as a secondary task, the step of application. This is due to the presupposition that this step of application, or implementation, will necessarily follow if the norm is valid.

\begin{abstract}
"Procedural ethical theories, in particular, first set themselves the task of indicating a procedure through which norms and modes of action can be rationally grounded or criticized, as the case may be. Because they must deal with this task separately, the impartial application of valid principles and rules arises only as a subsequent problem." [7]
\end{abstract}

It is clear in this quotation that procedural ethical theories make a distinction between the task of norm construction or norm criticism, which has to be rationally grounded, and the "impartial application" of the norm that has previously been constructed. This means that the demands of the problem of application are not taken into account in the theory that frames the norm construction process. The blind spot of procedural theories is the actual effect that the context of application has on the norm construction.

Procedural ethical theories have determined that the best way to ensure fair and "right" norms, that exclude bias and unresolved conflict, is through rational consensus on the part of every stakeholder. There are various examples of such rational consensus. They include the law of the better argument ${ }^{9}$ from Habermas' discourse ethics [5], the overlapping consensus ${ }^{10}$ from Rawls' political liberalism [17], and the

\footnotetext{
${ }^{7}$ Jürgen Habermas, Between Facts and Norms: Contribution to a Discourse Theory of Law and Democracy Cambridge, MIT Press, 1996, p. 296.

${ }^{8}$ Normativity is a property of norms. It is what gives the prescriptive impact to the norms. A normative statement is a statement regarding how things should or ought to be. The normative level is a level that is not attached to what things are, but how they should be.

${ }^{9}$ The law of the best argument implies that there is/will be an argument in the discussion, which will be the object of consensus and that is the most rational argument, which is to say, in that type of theory, the best one.

${ }^{10}$ Overlapping consensus involves that citizens accept and support the same basic rules, even if for different reasons. The overlapping consensus does not include reasons why someone agrees to a norm, but only the norm itself that everybody accepts whatever the reasons why they do so.
} 
problem of how to shape the discussion to validate and legitimate the norms that emerge. The theories cited are reluctant to include application in their construction and, more generally, to integrate the problem of context, because this would once again open the door to value conflicts. That door was closed so as to exclude values and beliefs as a source of legitimate norms in a rational debate.

However, a number of philosophers nowadays are criticising the reduction of ethics to rationality. The criticisms started with Simon and his theory of bounded rationality [20], and have not stopped since. Such thinkers as Lenoble and Maeschalck [10], [12], Sabel [19], Schön [21], Ferry [5], Sen [22], Von Schomberg [25], and many others, are now addressing the conditions and consequences of a re-inclusion of values, beliefs, context, narrative, interpretation, life experience, and everything that was left to one side as a result of the procedural turn in ethics that led to procedural theories of norm construction. Most philosophers remain within the broad trend of proceduralism, but want to open up its framing ${ }^{11}$ so as to open it up to more complexity ${ }^{12}$.

Lenoble and Maesschalck have criticised the development of this growing critique of the procedural approach [12]. They emphasize three presuppositions that are implied in a lot of ethical theories: the mentalist, intentionalist, and schematising presuppositions. These presuppositions are linked to their critique of the separation made by Habermas of the context of application from the context of justification.

In the intentionalist presupposition, the effects of norms are supposed to be deducible from the simple intention to adopt the norm. Additionally, there is the presupposition that the actors in a participatory approach will have the capacity and intention to contribute to the participatory discussion. The schematising presupposition involves Kantian schemes (i.e., rules developed by the philosopher, Immanuel Kant), in which the operation of the application of a norm is a simple formal deductive reasoning on the basis of the rule itself. The determination of the norm is linked to these rules, that include examples such as ethical guidelines, laws, or other external sets of rules. The mentalist presupposition is so named because it relies on the mind having a set of rules (or schemes, in Kant's words), that predetermines the effect of a norm and does not depend on any context exterior to that of the thinker. This is commonly seen

${ }^{11}$ The notion of framing covers everything that informs and conditions an action, an opinion or a research. It includes context, presuppositions, things that are considered normal in a society and everything that determines the shape and/or the content of a decision. There is no action and a fortiori no research without its own framing. Every epistemological choice frames a piece of research. A reflexive framing is necessary for good research (good research has to narrow the subject, define how it will be using concepts, methods, explain its objective, its starting hypothesis, the process of thought and experiment or tests that will come to test those hypotheses, and so on). The issue with framing is not its existence, it is whether people are conscious of it or not. That is where reflexivity has its part to play. Making people aware of their own framing, making people realize the presuppositions that are at stake when they act and think, is the first step in a process of changing behaviours to reach more ethical behaviours.

12 The same movement can be seen in the field of economics. There has been a shift from the paradigm of the "rational agent" to the acceptance of more and more complex models that include irrational behaviour. 
when participants in a participatory approach come to the setting with their own particular ethical framing, or with preconceptions as to what ethical issues might arise. As noted by the analysis of Lenoble and Maesschalck regarding governance and norms [12], it is the failure to account for the epistemological position of the social actors that leads to those presuppositions.

The position of the normative device (experts, guidelines, etc.) as a judging entity (exerting top-down pressure) does not permit the adequate elaboration of a governance approach. These presuppositions facilitate failure insofar as they underwrite inattention to the material that informs the perspective of any given social actor. Thus, they facilitate the elaboration of governance that has a built-in "gap" between governing and the governed. Another presupposition, identified by Ferry, is that most ethical theories and governance arrangements ignore that the conditions why we accept a norm are not equal to the condition of its justification [5]. This means that we can both accept a norm for reasons other than its rational justification, and without agreeing with its justification.

We have seen that there are many presuppositions on both sides. Ethical theories are failing to pay enough attention to their application in the field, and developers are failing to consider ethics as a complex task that cannot be reduced to some obvious issues and some convenient answers. Now we have to determine how we could overcome those presuppositions. However, as we will see, this is not a simple question, because we have to understand what our own presuppositions are whenever we are talking about the implementation of ethics in information systems.

Indeed, this way of talking about the problem of implementation raises a huge problem. Talking about implementation would mean that there is something to be implemented. But ethics is not a product. Ethics, as we have said, has to be a question. We cannot "sell" ethics as if it were a medicine to be taken, as if the only issue were to write and explain the instructions well enough to be understood entirely.

If ethicists, over the years, did try to influence ethics to become an instruction book to be applied by developers, technicians and scientists, by writing codes of conduct, checklists of ethical issues and assessment procedures, this method does not seem to work. This is because, by using that kind of approach, the philosophers who write the instructions do not offer the key to its understanding to the reader, so that the reader can understand the true meaning of the instructions on his/her own and, hence, learn to act ethically in an independent way.

Talking about implementation seems improper, because it does not involve the implications for and the engagement of developers. So, what could ethicists and technology developers together actually do to create technologies that are ethical, and to make the process of the development of a technology or an information system ethical?

\section{$4 \quad$ Hints Towards a Solution}

Two important hints are offered that could lead to eventual solutions. They include adapting ethical theories to their context of application, and reaching a form of ethical development for information systems. Each is explored in somewhat more detail below. 


\subsection{Adaptation of Ethical Theories to their Context of Application}

The identification of ethical issues is not sufficient to resolve the issues. The presupposition that identification was actually sufficient has been a brake to both ethical theories and ethical technological development.

In our research, we have found various forms of closure and presuppositions on the part of both the communities of "ethical people" and "technology people". There is also a gap between the two communities. The reasons for this include differences in "jargon", disinterest in implementation from the philosophers, disinterest in both ethics and its assimilation in laws from information systems' professionals, the separation between "human" sciences and "pure" sciences, notably in education, and so on. The role of ethics in recent years seems to be to open up framings and allow full reflexivity [21] for everybody, in order to create bonds between ethics and technology.

This approach involves reflexivity on the trends of ethical and governance research. This first is a task that has always been prevalent in the work of philosophers. Reflection on its own activity lies at the heart of philosophy. Putting that task back into the centre of the research in ethics is a good first step. However, the presuppositions in ethics are not really about reflexivity per se. The challenge might be that ethics researchers are too focused on the theories they are elaborating. The presupposition that a theory will answer all problems without being sensitive to the context of its application is still prevalent.

A good balance between reflexivity in ethics and a renewed interest in the context of the application of the theories has to be found. Our diagnosis, after research undertaken for three projects, EGAIS ${ }^{13}$, ETICA ${ }^{14}$ and IDEGOV, is that ethical theories have to take into account the context of application of their own theories, within the theory itself. That is to say that the theories must include an "opening" to challenges coming from the field to which they want to apply their theories, and to society in general.

The validity of the theories, ensured by ethical procedures, does not necessarily mean that the theories will actually be applicable. There is more to take into account than the legitimacy of the procedure to create norms. In the procedure, it should be acknowledged that the validity of a norm is not always sufficient to ensure its acceptance. Furthermore, somebody who can accept rationally a norm, and even help to create it within a discussion framed by ethical procedure (taking into account every argument, the law of the best argument, and so on), will not necessarily take that norm as a maxim for action [5].

\subsection{How to Reach Ethical Development of Information Systems}

We have said that information system is a particular field of application for ethics. We have also seen that the context of application has to be taken into account in the the-

${ }^{13}$ The EGAIS project was co-funded under the FP7 framework. See http://www. egaisproject.eu/

${ }^{14}$ The ETICA project was co-funded under the FP7 framework. See

http://ethics.ccsr.cse.dmu.ac.uk/etica/ 
ory. So how could we possibly take into account the context of information systems' development?

There are many presuppositions coming from the technical community about ethics. Ethics is generally seen as a constraint to be dealt with, more than an opportunity to "think outside the box" or even to improve the products under development. However, what is relevant for ethical theories seems to be also relevant to information systems' development. The context of the application of the product developed (here, an information system device) has to be taken into account as well as the acceptance of this technology by the public. The fact that information has such a positive value to society makes it easily accepted. However, there are a lot of issues, made stronger by the lack of wariness on the part of civil society. There are some ethical issues that are commonly admitted: privacy, security and surveillance. There are, however, issues that are more hidden, and that may depend on a particular situation. The question of trust, for example, cannot be reduced simply to privacy or security. Information systems touch questions of changes in time and space, changes in human interaction, the status of the person and a lot of other huge questions, which cannot be reduced to concepts that are on the edge of being deprived of meaning, due to their overutilisation $^{15}$.

Creating a list of issues is irrelevant. We have to think ethically all the time, and assess technologies as we develop them. It is not a matter of changing professional rules and code of conducts; it is a matter of changing professionals' thinking about ethics. There is no ethical thinking "to be implemented"; there is rather ethical thinking to be thought.

Taking part in the process of norm construction is a good first step for information systems' professionals, to open up their framing and gain awareness of their own presuppositions and of others' points of view. It is not because we agree with the norms that we comply with them. There is a need for constant reflexive thinking about the technologies developed and the systems created. Ethical thinking cannot be assumed to be something in the minds of the people, coming from general principle they agreed on explicitly or implicitly. That is why the gap between the ethical community and the scientific community is so tragic. As a society, we need to reduce that gap; we need to find common ground on which to collaborate.

In that process, both disciplines have to reassess their own positions, rethink their own presuppositions and discuss them. There is a need in both disciplines for secondlevel reflexivity, which is different from just thinking about its immediate action [1]. Reflexivity at a second level is much deeper. It involves questioning the maxim of its action and the presuppositions that are at its very basis. Those presuppositions can come from various sources: they can come from the structure of the society, the field in which one is working, or one's personal history, beliefs, and so on.

This is why one of the solutions we have to think about in ethics is narration in the process of norm construction. Not everything can be transformed into a rational

15 The same is true of the term "ethics", which seems to have lost a lot of its meaning to become either a derogatory term or a category into which every non-technical aspect of technology development that nobody knows how to address is put. 
argument. A life story is very often more powerful and convincing than a rational argument, and this fact has to be taken into account.

As for the assessment process of a technology, there is a need for a shift in the assessment procedure from an ethical analysis of the issues to a meta-ethical analysis of the governance process. This need has been discussed in both the EGAIS and IDEGOV projects, but is also the subject of lots of publications in the area of information systems. Harris et al. for example are developing a tool called DIODE [9], which is a meta-methodology aimed at offering guidance to professionals while avoiding reduction to a check-list or expert-driven assessments, by bringing together top-down and bottom-up approaches, and broadly by combining teleological and deontological ethical principles. These kinds of tools are a good step, especially when, like in DIODE, they include ethical training for the persons who would assess the technology. However, they are also often on the edge of falling into the presuppositions discussed earlier - reliance on procedures, not taking into account the acceptance of norms, the gap between rational acceptance and application, and so on.

A completely inclusive way to incorporate multiple sources of information within discussions about norms, in order not to reject them in the unthought-of area of presuppositions and prejudices, has still to be found. The way forward is to explore more carefully the relationship between ethics and technology. This means to try to overcome the presuppositions that undermine this relationship and construct a method that is fully aware of its own limitations, the limitation of the persons involved and yet which also takes into account every aspect of the context (in the broadest sense of the term, which includes the context of the persons involved: values, life experiences, and so on).

This solution involves being ready, as a society, to invest time into ethics. For both ethical and technological communities, it means to be ready to work together, with their differences but also without too neat a border, since ethics is something that anybody could think about, no matter what its speciality. Ethical responsibilities have to be shared but they have also to be taken by people in the creation and development process (and not only at the ethical assessment step).

\section{Conclusion}

The problem of implementation may appear as a "subsequent" problem in ethical theories. However, it is actually at the heart of the governance. In the last analysis, it touches the challenge of ethical norms construction, and the ethicity of norms. As we have seen, implementing ethics in information systems raises a lot of issues, both theoretical and practical.

The first reason is that the term "implementation" is already wrong. It is not really a matter of implementing ethical rules and codes of conduct for information systems' professionals, and technology developers in general. The way to overcome presuppositions in ethics and technology seems to be by trying to reach reflexivity by opening the framing of every stakeholder (by showing them the presuppositions they are working under). The first step towards this seems to be by finding ways to encourage ethics researchers and technology developers to work together. 
Because reflexivity at a second level is impossible to implement from an external point of view, we have to rely on what has already been developed in philosophy: discussion and procedures of norms construction. These procedures, however, are themselves subject to presuppositions, notably the fact that they are closed to the context of their own application, and that they deny legitimacy to a part of reality. (Indeed, irrationality exists, and people act as a result of other means and reasons than reason itself; they do not necessarily obey the best - the most rational - argument.)

So we have to create a proceduralism that would take into account more complexity than the current version of proceduralism that we have. Researchers in governance and ethics - including the authors - are currently in the process of systematising this approach in a theory which is called "comprehensive proceduralism". Comprehensive proceduralism goes a step further into the questions and explores the hints towards various answers given in this paper.

By exploring the presuppositions that lie in the background of the theories of ethical technology assessment, we give some keys to understand further the failures and successes of the current ways of undertaking ethical assessment. We also offer a more comprehensive framework in which it would be easier to collaborate, take on board others' perspectives, and find solutions that will already be "implemented" from the ground upwards at the very beginning of their conception because they will have taken into account the context of the application in their own construction.

\section{References}

1. Argyris, C., Schön, D.A.: Organisational Learning. A Theory of Action Perspective, vol. 1. Addison Wesley, Reading (1978)

2. Brey, P.: Method in Computer Ethics: Towards a Multi-Level Interdisciplinary Approach. Ethics and Information Technology 2(3), 1-5 (1999)

3. Duquenoy, P.: Ethics of Computing. Perspectives and Policies on ICT in Society. Springer \& SBS Media, Heidelberg (2005)

4. Gregg, B.: Proceduralism reconceived: Political conflict resolution under condition of moral pluralism. Theory and Society 31, 741-776 (2002)

5. Ferry, J.-M.: Valeurs et Normes, La question de l'éthique. Edition de l'université de Bruxelles, Bruxelles (2002)

6. Habermas, J.: The Theory of Communicative Action. English translation by Thomas McCarthy. Beacon Press, Boston (1981)

7. Habermas, J.: Erläuterungen zur Diskursethik. Frankfurt am Main, Suhrkamp (1991)

8. Habermas, J.: Between Facts and Norms: Contribution to a Discourse Theory of Law and Democracy. MIT Press, Cambridge (1996)

9. Harris, I., Jennings, R.C., Pullinger, D., Rogerson, S., Duquenoy, P.: Ethical assessment of new technologies: a meta-methodology. Journal of Information, Communication and Ethics in Society 9(1), 49-64 (2011)

10. Laudon, K., Laudon, J.: Management des systèmes d'information, 11th edn. Pearson Education, London (2011)

11. Lenoble, J., Maesschalck, M.: Toward a Theory of Governance, the Action of Norms (trad. Paterson, J.). Kluwer Law International, The Hague (2003) 
12. Lenoble, J., Maesschalck, M.: Beyond Neo-institutionalist and Pragmatic Approaches to Governance. Carnets du centre de philosophie du droit, Louvain-la-Neuve, no 130 (2007)

13. Masclet, L., Goujon, P.: IDEGOV D.1.1. Grid of Analysis, CIGREF Foundation (2011)

14. Masclet, L., Goujon, P.: IDEGOV D.3.2. Model of current and emerging governance strategies, Map of governance and ethics, CIGREF Foundation (2012)

15. Pearson, J.M., Crosby, L., Shim, J.P.: Modeling the relative importance of ethical behaviour criteria: A simulation of information systems professionals' ethical decisions. Journal Strategic Information Systems 5(4), 275-291 (1996)

16. Rainey, S., Goujon, P.: EGAIS 4.1 Existing Solutions to the Ethical Governance Problem and Characterisation of their Limitations (2009)

17. Rainey et al.: EGAIS 4.3 New Guidelines Addressing the Problem of Integrating Ethics into Technical Development Projects (2012)

18. Rawls, J.: A Theory of Justice. Harvard University Press, Cambridge (1971)

19. Sabel, C., Zeitlin, J.: Learning from Difference, The New Architecture of Experimentalist Governance in EU, European Governance Papers, Eurogov, C-07-02 (2008)

20. Simon, H.A.: Theories of bounded rationality. In: McGuire, C.B., Radned, R. (eds.) Decision and Organization, North-Holland Publishing Company, Amsterdam (1972)

21. Schön, D.: The Reflective Practitioner. How professionals think in action. Temple Smith, London (1983)

22. Sen, A.: The Idea of Justice. Harvard University Press, Boston (2009)

23. Stahl, B.C.: Ethical Issues of Information and Business. In: Himma, K., Tavani, H. (eds.) The Handbook of Information and Computer Ethics, pp. 311-337. Wiley, Hoboken (2008)

24. Van den Hoven, J.: Moral Methodology and Information Technology. In: Himma, K., Tavani, H. (eds.) The Handbook of Information and Computer Ethics, pp. 49-68. Wiley, Hoboken (2008)

25. Von Schomberg, R.: Discourse and Democracy: Essays on Habermas's Between Facts and Norms. State University of New York Press, New York (2002)

26. Webley, S.: Making Business Ethics Work: the foundations of effective embedding. The Institute of Business Ethics, London (2006)

27. Wiener, N.: The Human Use of Human Beings: cybernetics and society. The Riverside Press (Houghton Mifflin Co.), Chicago (1950) 